\title{
Patient satisfaction with anesthesia care services and associated factors in AHQ Hospital Bajaur Agency, KP, Pakistan
}

Ishtiaq Ahmad ${ }^{1}$, Emad Gohar ${ }^{2}$, Iqbal Noor ${ }^{3}$, Muhammad Basit ${ }^{4}$, Nimra Rehman $^{5}$ and Muhammad Tayyeb ${ }^{6 *}$

1. Trainee Medical Officer TMO, Department of Anesthesia, Khyber Teaching hospital Peshawar KP, Pakistan

2. Department of Anesthesia, Women and children hospital Rajjar Charsadda KP, Pakistan

3. Department of Anesthesia, Institute of paramedical science Peshawar KP, Pakistan

4. Department of Anesthesia, Institute of Paramedical Science, Khyber Medical University Peshawar, Pakistan

5. Department of Medicine, Shanxi Medical University, China

6. Department of Anesthesia, College of Medical Technology, Medical Teaching Institution, Bacha Khan Medical College, Mardan KP, Pakistan

*Corresponding author's email: tayyabm851@gmail.com

Citation

Ishtiaq Ahmad, Emad Gohar, Iqbal Noor, MuhammadBasit, Nimra Rehman and Muhammad Tayyeb. Patient satisfaction with anesthesia care services and associated factors in AHQ Hospital Bajaur Agency, KP, Pakistan. Pure and Applied Biology. Vol. 11, Issue 2, pp592-599. http://dx.doi.org/10.19045/bspab.2022.110060

\begin{tabular}{llll}
\hline \hline Received: 22/06/2021 & Revised: 25/08/2021 & Accepted: 02/09/2021 & Online First: 10/09/2021 \\
\hline \hline
\end{tabular}

\section{Abstract}

Patient satisfaction is the balance between expectation and perception of what is received. It is an important component and quality indicator in anesthesia care services. It can be affected by Anesthetist patient interaction, peri-operative anesthesia management, and post-procedure followup. There is no previous study conducted in our institute. This study aimed to assess the level of patient satisfaction with anesthesia care services and to determine the factors that affect patient satisfaction. Two hundred and sixty-three patients were selected among scheduled patients for a surgical procedure under different types of anesthesia were surveyed. The standardized questionnaire was used for post-operative patient interviews. Data was entered and analyzed through the Statistical Package for Social Science (SPSS) version 22. Overall, the proportion of patient satisfaction with anesthesia care services was $76 \%$. Of these, educated were less satisfied $(43.5 \%)$ compared with non-educated $(56.5 \%)$. Factors that affect patient satisfaction negatively are sore throat, shivering, peri-operative pain, nausea, and vomiting. Patient's satisfaction with anesthesia care services was low in our institute with previously many published studies. Factors that affect patient satisfaction negatively may be preventable and every health care provider should work on these factors to decrease dissatisfaction level. Awareness creation about the current problem and training need to be given for anesthetists.

Keywords: Anesthesia Care Services; Awareness; Peri-Operative care; Patient Satisfaction

\section{Introduction}

Satisfaction is a subjective feeling about the gratification of a desire, need, or the degree of congruence between expectations and accomplishment. While talking about patient satisfaction commonly allude to how well the patient surmises about the medical care services have been me [1]. To measure the 
degree of patient satisfaction different tools are used such as post-operative visit and through Questionnaire [2, 3]. The development of a patient-satisfaction tool needs a stepwise psychometric process and confirmation in practice, and due to the complex nature of satisfaction, questionnaires should use multiple items to examine specific events [4]. The actual standard of care that sufficiently exceeds this expectation can change a patient's initially negative judgment to a positive one. but simply, patient satisfaction depends on the comparison between what is expected by the patient and what happens to the patient $[2,5]$. Different factors contribute to patient satisfaction including accessibility and convenience of services that depend upon institutional structures, interpersonal relationships, competence of health professionals, and patient expectations and preferences [6].

Mediocre anesthesia services may discourage patients from using accessible services. Because of human concern, health concerns are most important [7]. During pre-operative and intra-operative it is very difficult to measure patients' satisfaction [8,9]. Quality of anesthesia is closely related to the incidences of pain, nausea and vomiting, and overall experience during the recovery period after the surgical process. Measurement of such attributes and parameters requires confirmation-based support in the form of objective scales along with subjective perceptions tested based on multiple dimensions by the primary assessor $[10,11]$. A study revealed that patients how are scheduled for the surgical procedure under general anesthesia and local anesthesia are (87\%) satisfied with anesthesia care services and $0.5 \%, 12.5 \%$ are unsatisfied and with no opinion respectively [12]. Another study concludes that among surgical patients $54.1 \%$ of patients coming in the category of less than $80 \%$ satisfied patients. Most importantly educated, American Society of anesthesiologist I II and female patients are less satisfied [7].

From a study conducted in Saudi Arab, corelate the dissatisfaction with post-operative nausea, poor control of post-operative pain, and severe dynamic pain. But overall satisfaction level was high $(95.2 \%)$ and unsatisfied was (4.8\%) [1]. A study done in Australia revealed that patient satisfaction level was high (96.8\%) and low-level unsatisfied patients were $(2.3 \%)$ and a strong level of unsatisfied was $(0.9 \%)$ [13]. The satisfaction level is higher in males compared to females and in general anesthesia than regional anesthesia among the Japanese population in the age of 20 to 39 years. The dissatisfaction level is (3.9\%) [14]. The process of assessing quality indicators and anesthesia outcomes is highly challenging and problematic in repetitive daily practice. In one of the systematic reviews, 108 quality indicators have been recognized and the common of them are considered to possibly affect the quality of anesthesia services. The remaining ones are also supportive of measuring surgical and post-operative care [15]. According to British anesthetist perception patient satisfaction with anesthesia care and personal care was significantly high with a single postprocedure visit compared with no visit at all [16]. Among Taiwan People responded with high satisfaction levels toward anesthesia care, personal care, waiting for operation theater, anesthesia staff attitude, and postoperative complication management [17].

A study was conducted at the University of Gondar hospital conclude that patient satisfaction with anesthesia care services was low compared with previously published literature. The major factor that contributes to inpatient satisfaction inclusive awareness, and proper training to anesthetists [18]. The patient's point of view remains the best way 
to measure patient satisfaction with anesthesia services [19]. In Asmara, Eritrea's population moderate level of satisfaction $(68.8 \%)$ was observed. Satisfaction level correlated with cooperative anesthesia staff, fair relationship with patients at the time of the procedure, and less fair $(87.5 \%)$ in patients [20]. Surgical patients require multiple factors to measure patient satisfaction. In the Australian population anesthesia care, satisfaction is high and cite different factor that could contribute to the dissatisfaction of patients [21].

The most common factor that contributes to patient satisfaction is the management of postoperative pain management, extubating period, nausea, and vomiting concluded by a study in Katihar [22].

A study demonstrates that involving a patient in the decision has a great role in patient satisfaction with anesthesia services [23].

\section{Materials and Methods}

\section{Study design, duration and setting}

This cross-sectional study was carried out from July 2016 to December 2016, at the department of anesthesia, at Agency Head Quarter Hospital (AHQ) Bajaur agency. Patients admitted to the AHQ and schedule for any surgical procedure involving both regional and general anesthesia were considered for our study.

\section{Sample technique, inclusion, and exclusion} criteria

Consecutive (Non-Probability) sampling was used and all those patients who had fulfilled our inclusion criteria were selected. A pretested questionnaire was used for data collection.

\section{Ethical approval and procedure}

The questionnaire translated verbally into the native language. Pre-test questionnaire was done on 30 patients in other hospital and some correction was made after data collection. Patients scheduled for elective surgical procedures were visited postoperatively, in their respective wards, after
Among the Greek population anesthesia care services satisfaction level lies in $(96.3 \%$ 98.6\%) [24].

If patient satisfaction can truly help to monitor the excellence of anesthesia care, a better measure of patient satisfaction that has recognized consistency and validity is needed. we attempt to lay the base for the creation of such a measure for anesthesia. We first review the method of patient satisfaction quantification and discuss the insufficiencies of existing measures in the anesthesia. We then framework the early important considerations distinctive to the setting of anesthesia that supports and monitors the construction of a more reliable and valid patient satisfaction questionnaire for anesthesia care.

In addition, hopefully, this study will be helpful as a footstep for the next research to be done in a similar area

24 hours of their operation. After explaining the aim of the study informed content was taken. Data collection is based on sociodemographic characteristics. The statistical tool used for data analysis was SPSS version 22. Mean and the standard deviation was calculated for numerical data and nominal data frequencies and percentages.

\section{Results}

Total of 263 patients scheduled for the surgical procedure under general anesthesia and regional anesthesia with a total satisfaction response rate of $(76 \%)$ during the study period. In most subjects (155) were male, including 113 patients who were educated. Among educated patients, 87 (43.5) were satisfied with anesthesia care services and 26 (41.26) were not satisfied. Of these 150 patients were non-educated. In non-educated patients $113 \quad(56.5)$ were satisfied and 37 (58.73) were not satisfied. Among most of the study subject, 155 $(76.7 \%)$ are shown in (Table $1 \& 2)$.

Of these 155 (58.93\%) were males and 108 (41.06) were female. Patients scheduled for 
minor surgery were $113(43 \%)$ and 150 $(57 \%)$ were admitted for major surgery. From these patients, $175(66 \%)$ were in ASA Class I, and $33(33.46 \%)$ in ASA class II are shown in (Table 3).

In total 263 pre-operative assessments were done in $257(97.7 \%)$ by consultant anesthetists. Anesthetist's approach was considered good by participating in 230 (87\%). And Patients with a chance to choose the type of surgery in elective surgery were 76 (28\%). And $158(60 \%)$ of respondents have a chance to ask questions and 105 (40\%) were deprived to ask questions are shown in (Table 4).

It was noted in $25(9.5 \%)$ patients in which $6(24 \%)$ participants are satisfied and $19(76 \%)$ are not satisfied. And in 238 participants $175(73.5 \%)$ were satisfied and $63(26.4 \%)$ were unsatisfied. Shivering is noted in $21(7.9 \%)$ patients in which $2(9.5 \%)$ were satisfied and 19(90.4\%). no shivering

Table 1. Educational status and Satisfaction was noted in 243 participants, in which 63 were unsatisfied. Sore throat noted in 30 $(11.4 \%)$ patients in which $11(36.6 \%)$ were satisfied and 19(63.3\%) were unsatisfied, while in remaining patients 63 were unsatisfied and 170 were satisfied.

Out of 263 patients, 53 (20\%) of patients were suffering from pre-operative pain while remaining were stable. A very few patients come with complain of intra-operative pain $20(7.6 \%)$. After post-operation visit 82 (31\%) patients complain of pain after procedure these data are shown in (Table 5).

Of these 175 participating post-operative complications inclusive sore throat was reported in 11 satisfied patients and in unsatisfied 19 patients were reported. As above shivering in satisfied patients is 02 and 19 in the previous one. Nausea and vomiting (06) and (19) were reported in satisfied and in unsatisfied respectively shown in (Table $6)$.

\begin{tabular}{|c|cc|c|c|c|}
\hline \multicolumn{2}{|c|}{ Count } & \multicolumn{2}{c|}{ Educational Status } & \multirow{2}{*}{ Total } \\
\cline { 3 - 6 } & Educated & Non-Educated & 200 \\
\hline Level of & & yes & 87 & 113 & 63 \\
\cline { 2 - 6 } Satisfaction & No & 26 & 37 & 263 \\
\hline \multicolumn{2}{|c|}{ Total } & 113 & 150 & \\
\hline
\end{tabular}

Table 2. Satisfaction Level and Gender

\begin{tabular}{|c|cc|c|c|c|}
\hline \multicolumn{2}{|c|}{ Count } & \multicolumn{2}{c|}{ Sex } & \multirow{2}{*}{ Total } \\
\cline { 3 - 5 } & Male & Female & 200 \\
\hline Level of & yes & 119 & 81 & 63 \\
\hline \multicolumn{2}{|c|}{ Totisfaction } & no & 36 & 27 & 263 \\
\hline \multicolumn{2}{|c|}{ Total } & 155 & 108 & \\
\hline
\end{tabular}

Table 3. Different characteristics of study participants

\begin{tabular}{|c|c|c|c|}
\hline S. No. & Characteristic & Frequency & Percentage \\
\hline \multicolumn{4}{|c|}{ Gender } \\
\hline 1 & Male & 155 & $58.93 \%$ \\
\hline 2 & Female & 108 & 41.06 \\
\hline \multicolumn{4}{|c|}{ Type of Surgery } \\
\hline 3 & Minor Surgery & 113 & $43 \%$ \\
\hline 4 & Major surgery ASA Status \\
\hline 5 & ASA I & 150 & $67 \%$ \\
\hline 6 & ASA II & 88 & $33.46 \%$ \\
\hline
\end{tabular}


Table 4. Patients assessment, Anesthesia approach, and other related information

\begin{tabular}{|c|c|c|c|}
\hline S. No. & Factor & Frequency & Percentage \% \\
\hline 1 & \multicolumn{3}{|c|}{ Pre-operative assessment } \\
\hline & Yes & 257 & $97.71 \%$ \\
\hline & No & 6 & $2.28 \%$ \\
\hline & Good & 33 & $87 \%$ \\
\hline & Bad & $12.54 \%$ \\
\hline & \multicolumn{3}{|c|}{ Anesthetists Approach } \\
\hline 3 & Patient well to choose the type of anesthesia \\
\hline & Yes & 76 \\
\hline & No & 187 \\
\hline & Yes & 158 & $71.1 \%$ \\
\hline & No & 105 & $60 \%$ \\
\hline
\end{tabular}

Table 5. Pain assessment pre, intra-operative, and post-operative

\begin{tabular}{|c|c|c|c|c|c|}
\hline S. No. & Factor & Frequency & $\begin{array}{c}\text { Percentage } \\
\%\end{array}$ & $\begin{array}{c}\text { Tolerable } \\
\text { pain } \\
\text { (Satisfied) }\end{array}$ & $\begin{array}{c}\text { Un tolerable } \\
\text { Pain } \\
\text { (Unsatisfied) }\end{array}$ \\
\hline 1 & Pain during Induction & & & & \\
\hline & Yes & 53 & $20 \%$ & $21(39.6 \%)$ & $32(60.3 \%)$ \\
\hline & No & 210 & $79.8 \%$ & $165(78.5 \%)$ & $45(21.5 \%)$ \\
\hline 2 & Intra-operative Pain & & & & \\
\hline & Yes & 20 & $7.6 \%$ & & \\
\hline 5 & No & 243 & $92.4 \%$ & & \\
\hline & Post-operative Pain & & & & \\
\hline & Yes & 82 & $31 \%$ & & \\
\hline
\end{tabular}

Table 6. Post-operative complications among satisfied and unsatisfied patients

\begin{tabular}{|c|c|c|c|c|c|c|c|}
\hline \multirow{2}{*}{ Satisfaction } & \multicolumn{2}{c|}{ Sore Throat } & \multicolumn{2}{c|}{ Shivering } & \multicolumn{2}{c|}{ Nausea and Vomiting } \\
\cline { 2 - 8 } & & Yes & No & Yes & No & Yes & No \\
\hline Yes & 181 & 11 & 170 & 02 & 179 & 6 & 175 \\
\hline No & 82 & 19 & 63 & 19 & 63 & 19 & 63 \\
\hline
\end{tabular}

\section{Discussion}

Peri-operative pain release and management have a significant role in consideration of the level of patient happiness and satisfaction with anesthesia care services in hospitals [25]. Overall, studies with patient satisfaction with anesthesia care services have a positive result as like in our study. This study aimed to find patient satisfaction with anesthesia care services and related factors. The finding of this study revealed the overall percentage of patient's satisfaction with anesthesia care services is $76 \%$ which is similar toa study done in Asmara, Eritrea with overall satisfaction percentage of $68.8 \%$ and $75 \%$ with staff-patient relation satisfaction [20]. Different studies with a similar questionnaire were published in Rwanda and Saudi Arabia. Patient satisfaction (61.9\%) was a little small than our study. And slightly less in Rwanda $(67.3 \%)[26,27]$. Baroudi et al. revealed that satisfaction level was less in females 
compared to males. And educated patients were less satisfied than uneducated. Over all, satisfaction was less than (85\%) [7].

A study in Ethiopia concluded the overall satisfaction $(65 \%)$ with the pre-operative period. A clinical audit showed that preoperative patient satisfaction is low. This could be inadequate information about anesthesia and their side effect [28]. The dimension of satisfaction explains about anesthesia, hospital stay, surgery, and their anesthesia complication. That's why overall, the satisfaction score was less than $(45 \%)$. This less satisfaction score is related to inadequate information provided to patients especially information related to anesthesia, their side effects, and complication $[28,29]$. A study done at Sohag University revealed that Inadequate pre-operative information and guidance will also the cause of dissatisfaction [27]. A study concludes that different factor which negatively affects the patient satisfaction level inclusive pain, cold, shortness of breath (SOB), nausea, and vomiting. Overall, the patient satisfaction proportion was $88.3 \%$ [30].

Peri-operative surgical information has a high impact on patient satisfaction. A study reported that peri-operative surgical services have $98 \%$ patient satisfaction. Health professional needs to emphasize perioperative information and guidance as, like surgical information, anesthesia-related communication, and guidance can improve the patient satisfaction of anesthesia care services [31,32]. The involvement of parturient in choice of anesthesia is a contributing factor for patient satisfaction with anesthesia care services. A study concludes that the lowest satisfaction was recorded with pre-operative services (17\%) and overall, maternal satisfaction (88\%) was associated with spinal anesthesia [33].

To increase patient satisfaction with anesthesia care services and decrease anxiety level train anesthetists should consult and exchange information with patients preoperatively [34]. Our study finding was low when compared with Caljouw et al. [20] (92\%) and Jlala et al. [29] (90\%). This score was high when compared with Rwanda's study percentage $(57 \%)$ of patient satisfaction [20].

In this study, there is a very less difference level of satisfaction between educated and un-educated patients. But female patients were less satisfied compared with male patients. After analysis of multivariable the main predictor of patient satisfaction anesthetist pre-operative assessment and anesthetic approach. The weakness noticed in this study was the patient's well to choose the type of anesthesia and question answering related to anesthesia. Among dissatisfied patients, the dissatisfaction is because of different factors like sore throat, perioperative Pain, Shivering, Nausea, and Vomiting. Most patients afraid of hospital stay long hospital stay and waiting time.

\section{Conclusion}

This study concludes that the overall level of patient satisfaction with peri-operative anesthesia care is $76 \%$. The presence of preoperative and postoperative complications leads to dissatisfaction with anesthesia care. While explaining the risk and benefit of anesthetic techniques to patients, patient opinion is very important while deciding the type of anesthesia. Patients describe, isa good anesthetic approach and better pre-operative assessment. Different factors associated with dissatisfaction may be preventable.

\section{Authors' contributions}

Conceived and designed the experiments: I Ahmad \& M Tayyeb, Performed the experiments: E Gohar \& I Noor, Analyzed the data: N Rehman \& M Tayyeb, Contributed materials/ analysis/ tools: I Ahmad \& I Noor, Wrote the paper: I Ahmad, E Gohar, \& M Tayyeb. 


\section{References}

1. Alshehri AA, Alomar YM, Mohammed GA, Al-Fozan MS, Al-Harbi MS, Alrobai KA \& Zahoor H (2015). A survey on postanesthetic patient satisfaction in a university hospital. Saudi J. Anaesth 9(3): 303-305.

2. Singh DA \& Sood J (2007). Influence of multi-level anaesthesia care and patient profile on perioperative patient satisfaction in short-stay surgical inpatients: A preliminary study. IJANBN 51(2): 106.

3. Bauer M, Bohrer H, Aichele G, Bach A \& Martin E (2001). Measuring patient satisfaction with anaesthesia: perioperative questionnaire versus standardised face-toface interview. Acta Anaesthesiol. Scand 45(1): 65-72.

4. Linder PS (1982). Toward a theory of patient satisfaction. Soc Sci Med 16(5): 577-582.

5. Tayyeb M, Faisal S, Abdullah, Ajmal M, Ahmad N, Arsalan M, Jehad, A, Haq B ul, Shah S K \& Jan QM (2020). Prediction of Difficult Intubation with the Modified Mallampati and Upper Lip Bite Test: A Cross-Sectional Analysis. J Biomed Sci 9(2).

6. Hall JA \& Dornan MC (1988). What patients like about their medical care and how often they are asked: A meta-analysis of the satisfaction literature. Soc Sci Med 935-939.

7. Baroudi D, Nofal W, \& Ahmad N (2010). Patient satisfaction in anesthesia: A modified Iowa Satisfaction in Anesthesia Scale. Anesth Essays Res 4(2): 85.

8. Gaszynski T, Jakubiak J, Woźniak K, Trafidło T, Ratajczyk P \& Gaszyński W (2011). Patient satisfaction with anaesthesia and pre-anaesthetic information. Anestezjol Intens Te 43(4): 214-219.

9. Gupta A, \& Gupta N (2011). Patient's experiences and satisfaction with preanesthesia services: A prospective audit. J Anaesthesiol Clin Pharmacol 27(4): 511515.
10. Heidegger T, Saal D \& Nübling M (2013). Patient satisfaction with anaesthesia - Part 1: Satisfaction as part of outcome - and what satisfies patients. $A A G B$ I68(11): 1165-1172.

11. Whitty PM, Shaw IH, \& Goodwin DR (1996). Patient satisfaction with general anaesthesia. AAGB I51(4): 327-332.

12. Wołowicka L, Trojanowska I, Bartkowska Sniatkowska A \& Buchwald E (2001). Patient satisfaction with anesthesia as a measure of quality of anesthesia care. Folia Med Cracov 42(4): 219-226.

13. Myles PS, Williams DL, Hendrata M, Anderson H, \& Weeks AM (2000) Patient satisfaction after anaesthesia and surgery: results of a prospective survey of 10811 patients. Br J Anaesth 84(1): 6-10.

14. Nakahashi K, Motozu Y, Sasaoka N, Hirai K, Kitaguchi K \& Furuya H (2020). Patient Dissatisfaction With Anesthetic Care Masui. 53(10): 1136-1142.

15. Young $S$ (2006). Interaction Between MAO-A Genotype and Maltreatment in the Risk for Conduct Disorder: Failure to Confirm in Adolescent Patients. Am J Psychiatry 163(6): 1019-1025.

16. Saal D, Heidegger $T$, Nuebling $M$ \& Germann R (2011). Does a postoperative visit increase patient satisfaction with anaesthesia care. Br J Anaesth. 107(5): 703-709.

17. Yang YL, Wang KJ, Chen WH, Chuang KC, Tseng CC \& Chien-Cheng Liu (2007). Improved satisfaction of preoperative patients after group video-teaching during interview at preanesthetic evaluation clinic: the experience of a medical center in Taiwan. Acta Anaesthesiol Taiwan 45(3): 149-154.

18. Gebremedhn EG, Chekol WB, Amberbir WD \& Flatie TD (2015). Patient satisfaction with anaesthesia services and associated factors at the University of Gondar Hospital: a cross-sectional study. BMC Res Notes 8: 377.

19. Capuzzo M \& Alvisi R (2008). Is it Possible to Measure and Improve Patient 
Satisfaction with Anesthesia. Int Anesthesiol Clin 26(4): 613-626.

20. Caljouw M A A, Van Beuzekom M, \& Boer F (2008). Patient's satisfaction with perioperative care: Development, validation, and application of a questionnaire. Br J Anaesth100(5): 637644.

21. Myles PS, Williams DL, Hendrata M, Anderson H \& Weeks AM (2000). Patient satisfaction after anaesthesia and surgery: results of a prospective survey of 10,811 patients. Br J Anaesth 84(1): 6-10.

22. Furuya H, Nakahashi $K$, Hirai $K$, Yoshikawa M, Kitaguchi K, Morooka T, Horiuchi T, Kurita N, Iwatsubo $\mathrm{T} \&$ Shimoda T (2001). Assessment of anesthesia satisfaction using direct interviews at post-anesthesia clinic. Masui 50(3): 240-245.

23. Flierler $\mathrm{W}$ J, Nübling, M, Kasper $J$, \& Heidegger $T$ (2013). Implementation of shared decision making in anaesthesia and its influence on patient satisfaction. Anaesthesia. 68(7): 713-722

24. Kouki P, Matsota P, Christodoulaki K, Kompoti M, Loizou M, Karamanis P, Pandazi A \& Kostopanagiotou G (2012). Greek surgical patients' satisfaction related to perioperative anesthetic services in an academic institute. Patient Preference and Adherence (6): 569-578.

25. Le May S, Hardy JF, Taillefer, MC \& Dupuis G (2001). Patient satisfaction with anesthesia services. Can J Anaesth 48(2): 153-161.

26. Leóntine \& Ingabire (2017). Patients satisfaction with perioperative care at Oshen Fing Feisal Hospital.

27. El-Nasser GA \& Mohamed N (2013). Patient Satisfaction with Preoperative Care and Its Relationship with Patient
Characteristics. Med J Cairo Uni 81(2): 110.

28. Gebremedhn E G, \& Nagaratnam V (2014). Assessment of patient satisfaction with the preoperative anesthetic evaluation. Patient Related Outcome Measures 105-110.

29. Jlala HA, Caljouw, MA, Bedforth NM \& Hardman J G (2010). Patient satisfaction with perioperative care among patients having orthopedic surgery in a university hospital. Local Reg Anesth 3(1): 49-55.

30. Benwu KM \& Gebremedhin HG (2019). A prospective study on elective surgical inpatient satisfaction with perioperative anaesthesia service at Ayder comprehensive specialized hospital, Mekelle, Ethiopia. BMC Anesthesiol 19(1).

31. Gebremedhn EG \& Lemma GF (2017). Patient satisfaction with the perioperative surgical services and associated factors at a university referral and teaching hospital: A cross-sectional study. Pan Afr Med (5)27: 176.

32. Thomas H, Saal D \& Nuebling M (2006). Patient satisfaction with anaesthesia care: What is patient satisfaction, how should it be measured, and what is the evidence for assuring high patient satisfaction. Best Pract Res Clin Anaesthesiol 20(2): 331346.

33. Idris IM, Weldegiorgis GG \& Tesfamariam EH (2020). Maternal Satisfaction and Its Associated Factors towards Spinal Anesthesia for Caesarean Section: A CrossSectional Study in Two Eritrean Hospitals. Anesthesiol Res Pract.

34. Soltner C, Giquello JA, Martin M \& Beydon, L (2011). Continuous care and empathic anaesthesiologist attitude in the preoperative period: impact on patient anxiety and satisfaction. $B \quad J$ Anaesth 106(5): 680-686. 